\title{
Infantile hypertrophic pyloric stenosis in Greater Manchester
}

\author{
J P WALSWORTH-BELL
}

From the North Western Regional Health Authority, Manchester M60 7LP, UK

SUMMARY An "unprecedented" rise in the incidence of infantile hypertrophic pyloric stenosis (IHPS) was reported from the Central Region of Scotland in 1979. ${ }^{1}$ Examination of statistics from Greater Manchester showed a similar trend in some district health authorities but not others. Possible explanations are examined but future research is required. Hospital Activity Analysis can provide a useful tool for such research.

Previous studies have described an incidence of infantile hypertrophic pyloric stenosis between two and four per 1000 live births in the United Kingdom. ${ }^{2}$ Geographical variations in incidence have been reported $^{34}$ and variations with time, ${ }^{56}$ although no previously reported incidence has been greater than four per 1000 live births.

\section{Methods}

Hospital Activity Analysis (HAA) was the main source of data for this study.

Records of patients admitted to one hospital but discharged from another were linked by comparing the recorded age, sex, place of residence, and the dates of the events. This covered direct transfer only.

Grouping identical case note numbers in a hospital's return provided a method of distinguishing between patients and events, or episodes, of inpatient care, and therefore of counting individual children.

The accuracy of the diagnostic coding was assessed by comparing the number of children with IHPS with the number who had had Ramstedt's operation, also obtained from HAA. In addition, case notes from four hospitals were examined to assess the accuracy of nearly half the recorded cases. This also provided an opportunity to collect further clinical data on these patients. Initially, data from the study covered the years 1974-9, so that only case records for these years were examined.

\section{Results}

Table 1 shows the numbers of children and the rate per 1000 live births residing in areas in Greater
Manchester who were discharged with this diagnosis from 1974 to 1980 . There was a general increase that was particularly pronounced in 1979 . First discharges of children with IHPS will approximate to its incidence as it is not a recurrent or chronic condition. Incidence rates varied considerably between areas, but all showed a peak in 1978 or 1979.

Table 2 shows the number of children discharged with a diagnosis of IHPS and those discharged after Ramstedt's operation. Generally, there were fewer children discharged having had Ramstedt's operation, but there were also some instances of the reverse. The case notes were examined, and where both IHPS and Ramstedt's operation were recorded there was no inaccurate or incomplete coding. Half the 14 cases recorded as IHPS without Ramstedt's operation were inaccurately coded, usually because pyloric stenosis had been included in an early differential diagnosis but not in the definitive diagnosis. Of the remaining seven cases, two had been treated medically but five were treated surgically and the operation was not coded. None of the 10 cases of Ramstedt's operation being coded without IHPS was inaccurate, but they were all incomplete (table 3 ).

\section{Discussion}

The first stage in deciding whether or not an apparent increase in the incidence of IHPS was "true" was examination of the completeness and accuracy of the statistics.

The overall completeness of HAA returns is usually assesssed by comparison with the event based statutory hospital return on form SH3. This is 
Table 1 Numbers discharged from hospital, 1974-80

\begin{tabular}{|c|c|c|c|c|c|c|c|c|}
\hline & & \multicolumn{7}{|c|}{ No of children discharged and rate per 1000} \\
\hline & & 1974 & 1975 & 1976 & 1977 & 1978 & 1979 & 1980 \\
\hline No & $\begin{array}{l}\mathbf{M} \\
\mathbf{F}\end{array}$ & $\begin{array}{r}52 \\
9\end{array}$ & $\begin{array}{l}55 \\
10\end{array}$ & $\begin{array}{l}73 \\
17\end{array}$ & $\begin{array}{l}63 \\
19\end{array}$ & $\begin{array}{l}86 \\
20\end{array}$ & $\begin{array}{r}121 \\
28\end{array}$ & $\begin{array}{r}108 \\
25\end{array}$ \\
\hline $\begin{array}{c}\text { Rate per } 1000 \\
\text { live births }\end{array}$ & $\begin{array}{l}\mathbf{M} \\
\mathbf{F}\end{array}$ & $\begin{array}{l}2.74 \\
0.51\end{array}$ & $\begin{array}{l}3 \cdot 11 \\
0.60\end{array}$ & $\begin{array}{l}4 \cdot 31 \\
1 \cdot 07\end{array}$ & $\begin{array}{l}3 \cdot 87 \\
1 \cdot 22\end{array}$ & $\begin{array}{l}5 \cdot 03 \\
1 \cdot 24\end{array}$ & $\begin{array}{l}6 \cdot 63 \\
1 \cdot 62\end{array}$ & $\begin{array}{l}5 \cdot 92 \\
0.84\end{array}$ \\
\hline
\end{tabular}

Sources: Hospital Activity Analysis, Regional Statistical Unit, OPCS Form SD2.

Table 2 Numbers of children discharged having had Ramstedt's operation $(R)$ and children discharged with a diagnosis of infantile hypertrophic pyloric stenosis (HPS)

\begin{tabular}{|c|c|c|c|c|c|c|c|c|c|c|c|c|c|c|}
\hline Sex & $\begin{array}{l}1974 \\
R\end{array}$ & IHPS & $\begin{array}{l}1975 \\
R\end{array}$ & IHPS & $\begin{array}{l}1976 \\
R\end{array}$ & IHPS & $\begin{array}{l}1977 \\
R\end{array}$ & IHPS & $\begin{array}{l}1978 \\
R\end{array}$ & $I H P S$ & $\begin{array}{l}1979 \\
R\end{array}$ & IHPS & $\begin{array}{l}1980 \\
R\end{array}$ & IHPS \\
\hline $\begin{array}{l}\mathbf{M} \\
\mathbf{F}\end{array}$ & $\begin{array}{r}39 \\
8\end{array}$ & $\begin{array}{r}52 \\
9\end{array}$ & $\begin{array}{r}45 \\
6\end{array}$ & $\begin{array}{l}55 \\
10\end{array}$ & $\begin{array}{l}74 \\
19\end{array}$ & $\begin{array}{l}73 \\
17\end{array}$ & $\begin{array}{l}43 \\
10\end{array}$ & $\begin{array}{l}63 \\
19\end{array}$ & $\begin{array}{l}78 \\
15\end{array}$ & $\begin{array}{l}86 \\
20\end{array}$ & $\begin{array}{r}103 \\
22\end{array}$ & $\begin{array}{r}121 \\
28\end{array}$ & $\begin{array}{l}81 \\
18\end{array}$ & $\begin{array}{r}108 \\
25\end{array}$ \\
\hline
\end{tabular}

Source: Hospital Activity Analysis, Regional Statistical Unit.

regarded as complete in terms of use of hospital beds, since it is limited and therefore a more straightforward compilation of hospital discharges by specialty. Completeness of HAA compared with SH3 varies from hospital to hospital, but there were no changes in completeness that could account for the variations in hospital discharges for IHPS.

The accuracy of diagnostic coding was high, but its completeness in terms of all relevant diagnoses varied. There was one hospital particularly in which Ramstedt's operation was not always coded. This could have happened because operation notes were not recorded separately but as part of the general notes and were therefore less obvious to the coding clerks. In instances where Ramstedt's operation was coded but not the diagnosis of IHPS other diagnoses had been suggested before the child came to surgery, particularly in one hospital, so that it was less easy to find the diagnosis of IHPS. In no case was a Ramstedt's operation recorded as performed

Table 3 Confirmation of HAA diagnosis. Number of records examined with diagnosis/operation of infantile hypertrophic pyloric stenosis (IHPS) or Ramstedt's procedure (R), or both, 1974-9

\begin{tabular}{lcll}
\hline & $\begin{array}{l}\text { Case notes } \\
\text { coded for both } \\
\text { IHPS and } R\end{array}$ & $\begin{array}{l}\text { Case notes } \\
\text { coded for IHPS } \\
\text { without } R\end{array}$ & $\begin{array}{l}\text { Case notes } \\
\text { coded for } R \\
\text { without IHPS }\end{array}$ \\
\hline Hospital A & 65 & 4 & 3 \\
Hospital B & 43 & 0 & 3 \\
Hospital C & 17 & 5 & 2 \\
$\begin{array}{l}\text { Hospital D } \\
\text { Total }\end{array}$ & 100 & 5 & 2 \\
No inaccurately & 225 & 14 & 10 \\
$\begin{array}{c}\text { coded (\% of total) } \\
\text { No incompletely } \\
\text { coded (\% of total) }\end{array}$ & $0(0.0)$ & $7(50.0)$ & $0(0 \cdot 0)$ \\
\hline
\end{tabular}

inappropriately - that is, with no evidence of a pyloric "tumour" at operation.

The observed differences in the incidence of IHPS between districts and over time were only marginally affected by these problems; they could not, therefore, be explained as statistical artifact. They could be the result of different referral patterns and trends in treatment. General practitioners in one area may treat children with IHPS at home rather than ? refer them to hospital. There are no statistics for morbidity in general practice to examine the possibility. Consultant paediatricians, however, thought it unlikely that many children would be treated at home, since the diagnosis of IHPS is relatively straightforward and the surgical treatment effective, thus encouraging complete referral of children with projectile vomiting to hospital.

In an attempt to validate this some prescription data for atropine methonitrate (Eumydrin) was obtained from the Department of Health. These data are based on a 1 in 200 sample of dispensed prescriptions and are available only for a regional health authority as a whole. There were considerable fluctuations from year to year and no trend comparable with that for hospital discharges for IHPS. There would therefore seem to be no consistent trend in hospital or home treatment that could account for the changes observed.

The condition occurs predominantly in boys. The reported male/female ratio is in the order of 4 to 1 or 5 to $1 .^{2}$ An apparent increase in some parts of Wales in 1979 was associated with an increase in the male/female ratio from 2 to 1 to 5 to 1 , which was taken to indicate the presence of an environmental factor acting on the susceptible sex. ${ }^{7}$ In Greater Manchester the overall male/female ratio declined 
slightly in 1977 and has remained constant at $4 \cdot 3$ to 1 in the past three years (table 4).

The seasonal variation found by some authors ${ }^{34}$ was confirmed. Overall, there was a higher incidence in children born in September and October (table 5), although the increases in later years were not confined to infants born in these months. Information on family history was obtained from the case notes of some of the patients as previously explained. It may be incomplete as one does not know if it were specifically asked for in every case. There were considerable fluctuations from year to year in the proportion of children with a family history of IHPS, which is partly a reflection of the small numbers. For example, identical male twins were admitted within a day of each other, both with IHPS confirmed at operation; they were two out of the five children with a family history in 1977 . There was no change in the proportion of children with a family history that was associated with the differences in incidence.

Information on feeding patterns was also obtained from the case notes which again may vary in completeness. A higher proportion of breast feeding or previously breast feeding mothers attended one hospital than others, and this hospital was in an area with an incidence of IHPS. The proportion of breast feeding mothers was much lower, however, in 1979, when the incidence of IHPS increased. Superficially this does not suggest that there is a strong relationship between feeding pattern and IHPS. One would also require information on the general prevalence of breast feeding to be able to draw any conclusions.

\section{Conclusions}

The incidence of IHPS seems to be increasing in Greater Manchester, with geographical and seasonal variations as in previous reports. ${ }^{34}$ There is no obvious explanation and further research is required. In the meantime it is intended to monitor the incidence of IHPS using HAA to obtain information over a longer period.

I am very grateful to Dr K M Adler, Dr R Greenham, and Dr J Burn who allowed me access to the case notes of children under their care, and to $\mathrm{Mr} \mathrm{A}$ Jolleys for providing so much information on children under his care. Richard Popplewell gave statistical advice. Professor Ian Leck provided much advice, Dr Tim David gave encouragement throughout the study, and Dr David Vaughan read the drafts.

Table 4 Characteristics of children with IHPS

\begin{tabular}{|c|c|c|c|c|c|c|c|}
\hline & 1974 & 1975 & 1976 & 1977 & 1978 & 1979 & 1980 \\
\hline \multicolumn{8}{|c|}{ Male : female ratio } \\
\hline No of boys & 52 & 55 & 73 & 63 & 86 & 121 & 108 \\
\hline No of girls & 9 & 10 & 17 & 19 & 20 & 29 & 25 \\
\hline Ratio (m to f) & $5 \cdot 8$ & $5 \cdot 5$ & $4 \cdot 3$ & $3 \cdot 3$ & $4 \cdot 3$ & $4 \cdot 3$ & $4 \cdot 3$ \\
\hline \multicolumn{8}{|c|}{ Mean age (weeks) boys only } \\
\hline Mean age (weeks) & $5 \cdot 1$ & $5 \cdot 8$ & 4.9 & $5 \cdot 2$ & $5 \cdot 7$ & $4 \cdot 9$ & $5 \cdot 2$ \\
\hline \multicolumn{8}{|c|}{ Family history mentioned in case notes } \\
\hline $\begin{array}{l}\text { No of children with positive family history } \\
\text { Percentage of all children with IHPS treated }\end{array}$ & 2 & 3 & 2 & 5 & 5 & 3 & \\
\hline in that hospital & $13 \cdot 3$ & $17 \cdot 6$ & $6 \cdot 7$ & $27 \cdot 8$ & $19 \cdot 2$ & 6.5 & \\
\hline
\end{tabular}

* Only available for three hospitals whose case notes were examined.

Table 5 Monthly variation in incidence, 1974-80

\begin{tabular}{|c|c|c|c|c|c|c|c|c|c|c|c|c|}
\hline & Jan & $F e b$ & Mar & $A p r$ & May & Jun & Jul & Aug & Sep & Oct & Nov & Dec \\
\hline $\begin{array}{l}\text { Incidence rates per tho } \\
\text { live births to } \\
\text { Greater Manchester } \\
\text { residents }\end{array}$ & 2.61 & 2.93 & 3.25 & 2.76 & 2.62 & 2.77 & $2 \cdot 81$ & $3 \cdot 10$ & 3.88 & $4 \cdot 19$ & 2.48 & 2.47 \\
\hline
\end{tabular}




\section{References}

${ }^{1}$ Kerr AM. Unprecedented rise in incidence of infantile hypertrophic pyloric stenosis. $\mathrm{Br} \mathrm{Med} J$ 1980; 281: 714-15.

${ }^{2}$ Leck I. Correlations of malformation frequency with environmental and genetic attributes in man. In: Wilson $\mathrm{JG}$, Fraser JC, eds. Handbook of teratology. Vol 3 Comparative, maternal and epidemiologic aspects. New York: Plenum; 1977: 243-324.

${ }^{3}$ Adelstein P. Fedrick J. Pyloric stenosis in the Oxford record linkage study. J Med Genet 1976; 13: 439-48.

${ }^{4}$ Walpole IR. Some epidemiological aspects of pyloric stenosis in British Columbia. Am J Med Genet 1981: 10: 237-44.

${ }^{5}$ McLean $\mathrm{M}$. The incidence of infantile pyloric stenosis in the north east of Scotland. Arch Dis Child 1956; 31: 481-2.

${ }^{6}$ MacMahon B, Record RG, McKeown T. Congenital pyloric stenosis-an investigation of 578 cases. British Journal of Social Medicine 1951; 5: 185-92.

${ }^{7}$ Dodge JA, Laurence KM, Webb AR. Unprecedented rise in incidence of infantile hypertrophic pyloric stenosis. $\mathrm{Br}$ Med J 1980; 281: 1069. 